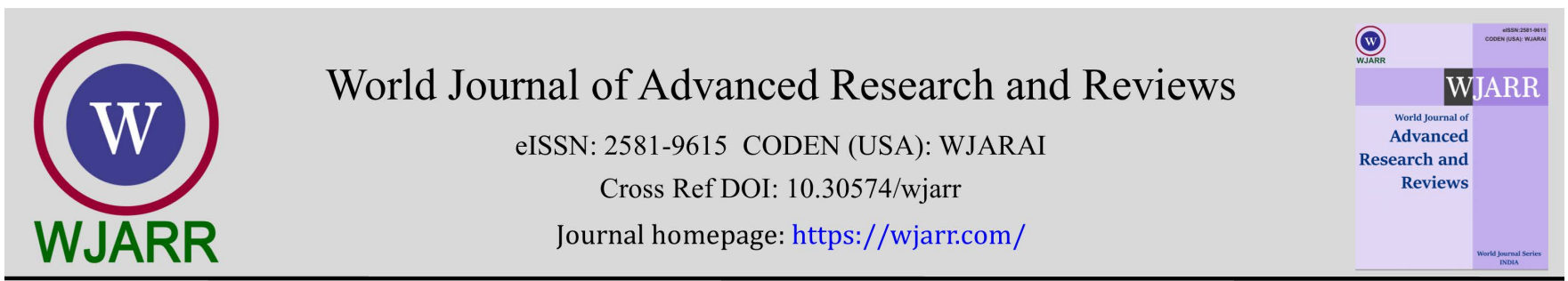

(RESEARCH ARTiClE)

Check for updates

\title{
Exploring a possible link between insulin resistance, vaccine to SARS CoV 2 and glycaemic disturbances in diabetes mellitus, type 2
}

\author{
ASV Prasad * \\ Former faculty member, Department of internal Medicine, G.I.T.A.M Dental collage, G.I.T.A.M University campus, \\ Rushikonda, Visakhapatnam, Andhra Pradesh, India.
}

World Journal of Advanced Research and Reviews, 2021, 11(01), 229-238

Publication history: Received on 05 June 2021; revised on 10 July 2021; accepted on 13 July 2021

Article DOI: https://doi.org/10.30574/wjarr.2021.11.1.0314

\begin{abstract}
The occurrence of both hyperglycaemia and hypoglycaemia, individually and in combination is reported in the literature, occurring in various insulin resistance (IR) syndromes, both to endogenous insulin, like Hirata disease, otherwise called the Insulin Autoimmune syndrome (IAS), type A, I R, Type B, IR etc. and to exogenous administered insulin, like, exogenous insulin antibody syndrome, (EIAS), non- classical auto immune syndrome to exogenous insulin, etc. Glycaemic disturbances without IR and in non-diabetics, like idiopathic and symptomatic reactive hypoglycaemias are also described in the literature. This author, recently reported for the first time, a biphasic post - vaccinal syndrome, following vaccination for Covid 19 (Covishield), causing glycemic disturbances in an elderly diabetes mellitus type 2 (DM2) patient on insulin who had moderate IR. Insulin resistance to exogenous insulin observed in the patient, is considered crucial for the occurrence of the observed clinical syndrome as, an increase or decrease of IR, and could explain the observed glycaemic disturbances. The IR to exogenous insulin, and the vaccine to Covid 19 , both have immunological basis. The immunological aspects of both IR and the Covid 19 vaccine are briefly reviewed to explore any possible interaction between the two, that could explain the observed clinical syndrome, referred to above. Also, the various underlying mechanisms for the glycaemic disturbances, in the above-mentioned IR syndromes and non-IR or $\mathrm{r}$ syndromes are explored as to shed some light on the mechanism of the glycaemic disturbances in the syndrome reported. A hypothesis is suggested, taking into consideration, the aforesaid observations. Apart from IR to exogenous insulin, other unidentified factors that might be causing the clinical syndrome reported, and which might account for its paucity of reporting, need to be investigated by future research.
\end{abstract}

Keywords: Insulin Resistance; immunoglobulins; Covishield ; Glycaemic disturbances

\section{Introduction}

Insulin resistance is defined as a normal or elevated insulin level, producing an attenuated biological response [1].It refers to impaired sensitivity to insulin mediated glucose disposal [2]. The incidence of insulin resistance in patients with diabetes was estimated to be $0.1 \%$ in a study at the Joslin Clinic between 1940 and 1960 [3] Insulin resistance is characterized by an impaired response to either endogenous or exogenous insulin.[4]. Besides, IR can be hereditary or acquired. The hereditary causes include mutations of the insulin receptor, the glucose transporter, and the signaling proteins. Acquired causes include physical inactivity, diet, medications, hyperglycemia due to glucotoxicity), increased free fatty acids, and the aging process [5]. It can occur in DM 1 or DM 2. The IR can be either immunological (caused by antibodies to insulin) or non-immunological, (usually genetic defects mentioned above). The various genetic diseases exhibiting IR, are mentioned under type A insulin resistance. (Vide infra) Immunological insulin resistance occurs in both DM 1 and DM 2. The focus of this article is on the exogenous IR, more so about its immunological aspects rather

\footnotetext{
${ }^{*}$ Corresponding author: ASV prasad

Department of internal Medicine, G.I.T.M Dental collage, G.I.T.A.M University campus, Rushikonda, Visakhapatnam, Andhra Pradesh, India.
}

Copyright $(2021$ Author(s) retain the copyright of this article. This article is published under the terms of the Creative Commons Attribution Liscense 4.0. 
than mechanisms of IR, which is reviewed extensively in the literature. The markers of this type of IR arehyperinsulinemia, central obesity, DM 2, hypertension, dyslipidemias, and a combination oof the preceding 3 conditions known as the metabolic syndrome, PCOD, Acanthosis Nigricans, etc.

\subsection{Some Insulin resistance syndromes}

- Type A IR is associated with receptor defect, genetic in origin and in the absence of any auto antibodies to insulin. Type A insulin resistance syndrome results from mutations in the insulin receptor gene (INSR). Type A insulin resistance syndrome is one of a group of related conditions described as inherited severe insulin resistance syndromes [6,7]. These disorders, which also include Donohue syndrome and Rabson-Mendenhall syndrome, are considered, a part of a spectrum.[8] Type A insulin resistance syndrome represents the mildest end of the spectrum.

- Type B is due to auto antibodies produced against the insulin receptor. Some patients present with symptoms of hypoglycaemia, such as sweating, tremulousness, irritability, and an altered level of consciousness. Hypoglycaemia results from interaction between insulin - mimetic antibodies and the insulin receptor. Some patients have insulin-binding antibodies directed against insulin, which, upon dissociation, can cause hypoglycaemia. Symptoms related to immunologic disease (eg, arthralgia, swollen salivary glands, hair loss) may occur. Some patients may present with hypoglycaemia due to agonistic activity of anti-insulin receptor antibodies [9]..Type B insulin resistance often occurs to patients with autoimmune diseases, such as systemic sclerosis, systemic lupus erythematosus and Sjogren's syndrome [10].

- Type C IR: F Nakamura et al [11]. reported type C IR which is familial, autosomal dominant (AD) and associated with short stature and intracellular beta-subunit mutations of insulin receptor which showed decreased kinase activity. Cases with deletion of the tyrosine kinase domain of the insulin receptor and the other with a Glycine1008 to Valine mutation, are also reported.

\subsection{IR to exogenous insulin}

Resistance can occur to even exogenous insulin injected. The emphasis of the present article, is on this type of IR. Insulin resistance can be defined as a daily insulin dose requirement that exceeds the normal daily pancreatic output in the nondiabetic state, i.e., approximately $40 \pm 20$ IU. Severe insulin resistance is usually defined as insulin requirement of more than $200 \mathrm{I} \mathrm{U} /$ day for at least 2 days [12]. Patients who require $>1 \mathrm{unit} / \mathrm{kg} /$ day are considered to have insulin resistance, and those requiring $>2$ units $/ \mathrm{kg} /$ day have severe resistance. The incidence of insulin $\mathrm{ln}$ at least $60 \%$ of patients diagnosed with immunological insulin resistance, the onset was after 30 years of age, suggesting that the syndrome is more commonly in type 2 diabetes [13]. The duration of insulin therapy before the onset of severe insulin resistance has been reported to range from 1 month to 15 years, although $50-85 \%$ of patients with insulin resistance received insulin for less than $1 \mathrm{yr}$, and 10-25\% received insulin for less than 1 month before the onset of severe insulin resistance [14]. The cause of IR in this case is immunological. The antigenic nature of exogenous insulin stimulates in the human body, the production of antibodies when injected. These insulin antibodies (IAs) interfere with the action of the exogenous insulin, thus reducing its capacity to neutralize the blood sugar, (BS) resulting in IR. All exogenous insulins are immunogenic. They differ in degree only. Berson and co-workers reported that clinical hypersensitivity and insulin resistance were associated with circulating insulin antibodies (IAs) in patients receiving exogenous animal insulin therapy [15]. The animal insulins (both bovine and porcine) have the highest immunogenicity, for which reason they are replaced by synthetic human insulins including the recombinant and analogue insulins. Immunogenicity is reported due to recombinant insulins but to a lesser extent than the animal insulins. The analogue insulins even, have the least immunogenicity. Insulin resistance tò exogenous insulin is often associated with symptomatic hyperglycaemia, including episodes of ketoacidosis and hyperosmolar coma [16]. The exogenous insulin is reported to cause both, Insulin resistance/ hyperglycaemia [17]. And hypoglycaemia [18].

\subsection{Syndromes of hypoglycaemia associated with exogenous insulin résistance}

\subsubsection{Exogenous insulin resistance antibody syndrome (EIRS)}

Xiaolei Hu and Fengling Chen et al (2018) [19]. named the spectrum of immunological responses to exogenous insulin as 'exogenous insulin resistance antibody syndrome (EIRS). This is characterized by patients who had high level of IAs, hypuerinsulinemia, who are exposed to exogenous insulin and develop spells of hypoglycaemia . Most patients tend to experience hypoglycaemia at night and hyperglycaemia during the day. This dual effect is explained as follows The IAs reversibly combine with exogenous insulin, inducing immunological insulin resistance, which leads to a higher postprandial BS level. When bound insulin dissociates, due to the change in non-classical IAS induced by IR to exogenous insulin, hypoglycaemia occurs. 


\subsection{Non- classical IAS induced by IR to exogenous insulin}

Shen, Y., Song, X. \& Ren, Y.et al [20]. described this syndrome, which is similar to classical IAS, but differed by occurring previously exposed patient to exogenous insulin. High levels of insulin autoantibodies, as well as hyperinsulinemic hypoglycemia, are found in patients with diabetes mellitus type 2 with prior exogenous insulin exposure. This entity is classified as non-classical IAS, by the authors.

\subsubsection{Persistence of IR to exogenous insulin even after Cessation of the treatment with it.}

Miho Hirano, Hiroshi Arima et al [21] reported persistent IR to exogenous insulin on Cessation of therapy which they attribute to insulin antibodies (IAs) due to endogenous insulin.

The exogenous insulin IR syndromes need to be differentiated from other cause of hypoglycaemia mentioned below

- $\quad$ Autoimmune Insulin syndrome (AIS) also called Hirata disease, in which spontaneous hypoglycaemia due to insulin autoantibodies, occurs in patients without previous insulin exposure [22]. It is due to $s$ a form of type VII hypersensitivity, characterized by the presence of autoantibodies against a circulating antigen. Due to their high binding capacity, IAs are capable of binding several molecules of insulin, resulting in the formation of large antigens-antibodies complexes. They have low affinity for insulin which is responsible for a significant spontaneous dissociation rate, which nay appropriately raise unbound insulin concentrations, thus resulting in hypoglycaemic episodes. High binding capacity and low affinity are the specific features of the IAs that are capable of inducing insulin auto antibodies (IAA). But in case of the insulin antibodies (IAs) that develop following exposure to exogenous insulin are more often characterized by a higher affinity and a lower binding capacity, compared to IAA. As a consequence, they mostly result in smaller antigen-antibody complexes which have a lower spontaneous dissociation rate, thus they are unable to produce significant glycaemic fluctuations.

- Idiopathic and symptomatic reactive hypoglycaemia or post pranideol hypoglycaemia is characterised by sudden hypoglycaemia occurring 3 to 4 hours after lunch caused by persistence of insulin even when BS after lunch is normalised. It is considered as a forerunner of DM2. The symptomatic causes like the dumping syndromes and insulinoma need to be excluded before considering the syndrome as idiopathic. Symptomatic reactive hypoglycaemia is due to the dumping syndromes following gastric surgery and insulinoma

- Post prandial syndrome: In this condition the patient experiences the symptoms of post prandial hypoglycaemia but the blood sugar is normal. This is due to autonomic adrenergic counter regulation.

\subsection{IR in D M 1}

Insulin resistance may be more common in T1D and was demonstrated as early as 1982 by DeFronzo et al [22]. Poor glycaemic control in type 1 diabetics is associated with hepatic insulin resistance, while whole-body glucose utilization was reported to be lower even in those who were well controlled [23, 24]. Type B IR is reported in DM 1.

\subsection{The double diabetes}

The term 'double diabetes,' coined in 2001, describes individuals who have

DM 1 autoantibody positivity but develop significant insulin resistance $[25,26]$.

\subsection{Measurement of insulin resistance}

Glycaemic-hyperinsulinemic clamp is the "gold standard" method for measuring insulin resistance is the clamp [27]. In which a constant intravenous infusion of insulin is balanced by a simultaneous infusion of glucose in a clinical research setting $[28,29]$. This test is cumbersome and time taking and hence is bot used for clinical or epidemiological purposes but is confined to research purposes.

Manish Gutch, Sukriti Kumar, Syed Mohd Razi, et al reviewed the tests in use for testing insulin sensitivity. They classified them into those tests useful clinically and those useful for epidemiological purposes. The former is HOMA-IR, QUIKI, and Matsuda while the latter group consists of HES, McAuley, Belfiore, Cederholm, Avignon and Stumvoll index [30]. 


\section{Discussion}

\subsection{Immune hypoglycaemia-due to immune antibodies}

Autoimmune Hypoglycaemia in a Type 2 Diabetic Patient with Anti-Insulin and Insulin Receptor Antibodies is reported. The insulin receptor antibody causes

- Inhibition of insulin binding to insulin receptors

- Accelerated receptor degradation

- Receptor -down regulation

- And extreme insulin resistance and hyperglycemia . Insulin receptor act as agonists or antagonists to the insulin receptor.

- Insulin receptor antibodies may - also inhibit insulin binding, thereby inhibiting insulin clearance and elevating levels of plasma insulin.

\subsection{Immunology of exogenous insulin resistance}

\subsubsection{Immunoglobulin classes in response to exogenous insulin}

IA responses consisting of virtually all Ig classes and IgG subclasses have been reported. Insulin-specific antibodies are primarily composed of IgG1-4 antibodies [31]. IgG antibodies have been associated with cases of severe insulin resistance [32, 33]. IgM, IgA, and IgE have been reported. Anti-insulin IgM has been detected during early insulin treatment [34] and both Andersen and Reisman et al [35]., reported the presence of that class in patients with immunological insulin resistance. However, Faulk et al. Reported detectable IgA in patients, and Kniker et al. [36] associated IgA with allergic reactions in patients with diabetes Immunological responses of exogenous insulin.

\subsubsection{Low affinity/high capacity and high affinity/low capacity IAs}

IAs can be divided into two populations: low affinity/high capacity and high affinity/low capacity. The former is commonly responsible for severe Insulin autoimmunity syndrome (IAS) patients with insulin autoantibodies, which is lead to postprandial hyperglycaemia and nocturnal hypoglycaemia, (as already seen above, whereas the latter is associated with Exogenous Insulin Antibody Syndrome (EIAS), (vide infra) which is typically accompanied by severe insulin resistance.

\subsubsection{Immunological responses seen with exogenous $I R$}

The various immunological responses noted in case of exogenous insulin are exhaustively reviewed by SE Fineberg et al INS [37]. These include

\section{Hypersensitivity reactions}

- Type 1. hypersensitivity: Hanauer A, Batson J.reported anaphylaxis to injected exogenous insulin. [38]. Local, immediate reactions are the least common cutaneous insulin reactions, occurring in less than $1 \%$ of patients [39].

- Type 3 hypersensitivity: An Arthus type of local reaction caused by vasculitis due to soluble antigen antibody reaction was reported. [40].

- lipoatrophy or loss of fat at insulin injection sites-may represent a persistent, localized Arthus reaction.

- Type 4 hypersensitivity: Local, delayed reactions are the most common hypersensitivity reaction and usually occur at the start of insulin therapy [41].

\subsubsection{Relation between the immune insulin antibodies and HLA system}

Insulin autoimmune hypoglycaemia is correlated in Asian races $(2,3)$ to certain HLA systems, like. Such as DR4 and DQw3, and especially DRB10406/DQA1 0302/DQB1 0302. Suggesting the existence of a predisposing genetic component. This relation with HLA system varies with the contry/ethnic groups. HLA-DRB1*0406 is quite prevalent in Japanese patients. 


\subsubsection{Immunological aspects of Covid 19 vaccine}

The viral factors

Immunogenicity of spike protein

The most immunogenic part of the SARS CoV 2 is the spike protein, (S) a glycoprotein. Both the Covishield and Covaxin vaccines target the spike protein. There are at least 3 spike protein domains against which host directs its immune response. They are the receptor binding domain (RBD), the $\mathrm{N}$ terminal domain (NTD) and S2 (a sub unit of the binding protein). RBD protein helps virus attach to ACE 2 receptor and hence a major target for vaccines. NTD incites the neutralizing antibodies and is highly mutable domain. S2 binding domain facilitates the fusion between viral envelope and the plasma membrane of its target. The other binding domain, namely S1 is involved in host cell receptor recognition and binding and causing confirmation changes in S2. The other viral proteins not targeted by the above two vaccines are the Capsid (C) protein and the envelop protein. (E)

\section{The host response}

Both humoral and Cell mediated immunity (CMI) are elicited in the host's body. The humoral response is of particular interest in the present context because of possible interaction between it and the immune reaction due to exogenous insulin. The predominant antibody produced is the neutralizing antibody targeting the MBD domain and less so, the S1 sub unit. About 84 percen of antibodies targeted other portions of the spike protein than the RBD. This suggests a successful immune response doesn't concentrate on the production of antibodies to RBD, but it also involves production of antibodies capable of covering areas across the entire spike. The nature of these 'other antibodies' is not delineated, but this fact comes handy to the proposed hypothesis (vide infra). The initial antibody is of ig M class of antibodies (also called natural antibodies) which are week in offering protection and are transient to be replaced by the Ig G antibodies which confer the lasting immunity.

The host -virus interaction

During the host-virus interaction a number of immunoglobulins are detected, depending on the stage of infection. Their significance is summarized in table 1.

Table 1 Antibodies classes produced during Covid 19 and their interpretation

\begin{tabular}{|l|l|}
\hline \multicolumn{2}{|l|}{ Serological test finding } \\
\hline Ig M negative & $\begin{array}{l}\text { Not infected (Ig M has a window period 4-7 days. PCR } \\
\text { to decide the status during the window period }\end{array}$ \\
\hline Ig M positive, Ig G negative & Early infectious phase of the disease \\
\hline Ig M positive, Ig G positive & Intermediate infectious phase of the disease \\
\hline Ig M negative Ig G positive & Recovery phase, noninfectious \\
\hline
\end{tabular}

\subsection{The hypothesis proposed}

\subsubsection{The backdrop}

- This hypothesis is intended to explain the biphasic glycaemic disturbance, following Covishield vaccine administration, in a 73-year-old male patient. He is on Human recombinant insulin (both bolus and basal) to which he showed moderate IR.This case report by this author, is the first of its kind [42].The salient case findings stage-wise, their interpretation as to the cause and the correlation with immunological events following the Covid vaccination are briefly presented in table 1.Full details may be accessed from the article cited. 
Table 2 Clinical observations, their interpretation and immunological correlation of events following vaccination for Covid 19

\begin{tabular}{|c|c|c|}
\hline Clinical observation & Clinical explanation & $\begin{array}{l}\text { Immunological } \\
\text { correlation }\end{array}$ \\
\hline $\begin{array}{l}1 \text { Stage of Hyperglycaemia } \\
\text { (Lasting about } 2 \text { cweeks) }\end{array}$ & $\begin{array}{l}\text { Increased insulin resistance/decreased } \\
\text { sensitivity to insulin }\end{array}$ & $\begin{array}{l}\text { Appearance of Ig M } \\
\text { antibodies }\end{array}$ \\
\hline $\begin{array}{l}2^{*} \text { Apparently return of BS level to pre- } \\
\text { vaccination levels } \\
\text { (About } 5 \text { to } 7 \text { days) }\end{array}$ & Return of IR to pre-vaccination level & $\begin{array}{l}\text { Decline of Ig } \mathrm{M} \\
\text { antibodies }\end{array}$ \\
\hline $\begin{array}{l}3 \text { Stage of hypoglycaemia } \\
\text { (About } 6 \text { weeks) }\end{array}$ & I**increased insulin sensitivity/ decreased IR & $\begin{array}{l}\text { Appearance of Ig G } \\
\text { antibodies }\end{array}$ \\
\hline $\begin{array}{l}4 \text { returns to normal of BS to pre } \\
\text { vaccination levels with prevaccination } \\
\text { doses of insulin } \\
\text { (About a week) } \\
\text { The total observation period is about } 10 \\
\text { weeks) }\end{array}$ & $\begin{array}{l}\text { *** Return of insulin resistance to } \\
\text { prevaccination level. } \\
\text { BS control with prevaccination dose of } \\
\text { insulin, without any episodes of } \\
\text { hypoglycaemia. }\end{array}$ & $\begin{array}{l}\text { Decline of Ig G } \\
\text { antibody titre. }\end{array}$ \\
\hline
\end{tabular}

It is obvious from above considerations that, the IR to exogenic insulin as well as the Vaccine, both cause induction of immune responses. There is even a parallel between the two immune responses at a given point of time, in that, the humoral response yields the same immunoglobulin classes, when the immune responses unfold. It is possible, that interaction between the two immune responses could possibly lead to the post -vaccination glycaemic disturbances reported in the case under consideration. The connecting link could be the insulin resistance to the exogenous insulin. Increase and decrease of IR, can cause both the observed hyperglycaemia and hypoglycaemia, respectively. Now what is left is to find out how these changes in IR could occur, which constitutes precisely, the core of the hypothesis. We have a precedent to such events, as seen in the various syndromes resulting from IR to both endogenous and exogenous insulins described in the literature and which have been briefly reviewed above. The principles of mechanism of the various hyperglycaemia /hypoglycaemia syndromes offer a clue to the syndrome observed presently.

The hyperglycaemia and hypoglycaemia following Covid 19 vaccination, is sought to be explained by the increased insulin resistance/ decreased insulin sensitivity and decreased IR /increased insulin sensitivity, respectively. The increased IR causing decreased sensitivity to insulin, makes the existing dose of insulin, ineffective in keeping the BS levels normal, any longer. All the known causes of IR, that increase the insulin demand and, necessitating an upwards revision of the existing insulin dose. Peculiarly, the stage of hyperglycaemia reported due to this post-vaccination syndrome, is not only managed without increasing the insulin dose, as daily BS monitoring during this period showed a decrease in IR as evidenced by BS levels showing the tendency to return to normal, obviate the necessity to increase the existing dose .Obviously the cause of this hyperglycaemia is transient, spontaneous and self-limiting which is against the probability of the cause being any of the known causes that increase the insulin demand. Now it is incumbent to explain how the The changes in the IR / sensitivity occur at each stage of the clinical syndrome are outlined in table 2.

Ig $\mathrm{M}$ antibodies are first to be formed either after exposure to any infection (including Covid 19) or on vaccination, against any infectious disease. Innate immunity is stimulated by a vaccine, beside its target antibody, but also against diseases other than the intended target of that vaccine. specific ig $M$ antibodies are detectable in both the situations. IgM is sometimes called a "natural antibody", as they are present in the blood before or even without being stimulated by any antigen. This phenomenon is probably is due to the high avidity of Ig $M$ that allow it to bind detectably even to weakly cross-reacting antigens Besides, Ig $\mathrm{M}$ in normal serum is often found to bind to specific antigens, even in the absence of prior immunization.[49]. The specific ig $M$ antibodies to exogenous insulin itself may be recalled by the anamnestic reaction, just like the positive widal in the fevers, other than of enteric fever. The Ig M is hexavalent antibody having 6 binding sites and has high binding capacity and low sensitivity. By virtue of its high binding capacity, it binds 
to the antigenic exogenous insulin, which is in excess of those IAs, binding to it and thus increasing the existing degree of IR. The net effect is increased binding to exogenous insulin resulting in increased resistance and consequently, the post-vicinal hyperglycaemia, reported. Further, the appearance of the Ig $\mathrm{M}$ has a window period of 4 to 7 days and hence the hyperglycaemia may not be detected immediately after the vaccination for Covid 19. This corresponds to early infectious phase as indicated in table 2, following natural infection with SARS CoV 2 infection. It is known that Ig M becomes gradually undetectable, in about 6 weeks' time. When this happens, the extra IR due to this binding to the exogenous insulin, also returns to pre-vaccination levels. This reversibility of competing with exogenous insulin is facilitated by the low sensitivity of the Ig M antibodies. The return to normal levels of IR /BS is spontaneous, self-limited and hence the hyperglycaemia does not need any increase in insulin dose as indicated in the case reported. With the return But, this period is short lived, as is the normalization of BS levels. That is why this stage is called "apparent return to normalcy". This corresponds to the transitional stage between serological stages of IgM negative, Ig G positive. The duration of hyperglycaemia lasted approximately, 2 weeks, as is the case with the presence of Ig M antibodies, suggesting further connection between the two.

Table 3 Review of basic tenets of immunology on which the hypothesis is founded are summarized in Table 2

\begin{tabular}{|c|c|c|}
\hline \multicolumn{3}{|c|}{ Some basic tenets of immunology on which the proposed hypothesis is based } \\
\hline Antibody related & Antigen related & Antigen-Antibody related \\
\hline $\begin{array}{l}\text { 1. An antibody can have two } \\
\text { completely independent binding } \\
\text { sites (paratrope) for unrelated } \\
\text { epitopes } \\
\text { (Richards et al. 1975).[43] }\end{array}$ & $\begin{array}{l}\text { Each antigen typically has many } \\
\text { epitopes. (Antibody binding sites } \\
\text { on the surface of the antigen) For } \\
\text { example, insulin, a dimeric } \\
\text { protein with } 51 \text { amino acids, has } \\
\text { on its surface at least } 115 \\
\text { antibody epitopes (Schroer et al. } \\
\text { 1983).[44]. Nearly the entire } \\
\text { surface of an antigen presents } \\
\text { many overlapping domains that } \\
\text { antibodies can discriminate as } \\
\text { distinct epitopes (Benjamin et al. } \\
\text { 1984) [45]. }\end{array}$ & $\begin{array}{l}\text { Binding forces of epitope and } \\
\text { paratrope: } \\
\text { Occurs through a variety of different } \\
\text { types of bonds such as Hydrogen } \\
\text { bonds, ionic bonds, Van der Waals } \\
\text { interactions and electrostatic force } \\
\text { The Antibody binding capacity (ABC) } \\
\text { is the number } \\
\text { monoclonal antibodies a sample } \\
\text { will bind, and correlates to the } \\
\text { number of antigens expressed on the } \\
\text { cell surface. . }\end{array}$ \\
\hline $\begin{array}{l}\text { 2. An antibody presumably has many } \\
\text { overlapping paratropes that can } \\
\text { potentially bind to a variety of } \\
\text { related or unrelated epitopes. }\end{array}$ & $\begin{array}{l}\text { Different related and un related } \\
\text { antibodies can bind to one } \\
\text { antigen. }\end{array}$ & $\begin{array}{l}\text { The Antibody binding capacity (ABC) } \\
\text { Itis the number } \\
\text { monoclonal antibodies a sample } \\
\text { will bind, and correlates to the } \\
\text { number of antigens expressed on the } \\
\text { cell surface. }\end{array}$ \\
\hline $\begin{array}{l}\text { 3. a single paratope can bind two } \\
\text { unrelated } \\
\text { (mimotopes, Pinilla epitopes } \\
\text { 1999;[46] Gras-Masse et et } \\
\begin{array}{l}\text { 1999). Kramer et al. [47] } \\
\text { el. }\end{array}\end{array}$ & $\begin{array}{l}\text { An antigen may induce more than } \\
\text { one type of antibody, as } \\
\text { exemplified by spike protein RBD } \\
\text { domain. }\end{array}$ & $\begin{array}{l}\text { Paratopes and epitopes define } \\
\text { complementary regions of shape and } \\
\text { charge rather than particular. Amino } \\
\text { acid compositions. }\end{array}$ \\
\hline $\begin{array}{l}\text { 4. A particular epitope can be } \\
\text { recognized by two different } \\
\text { paratroopers with no sequence } \\
\text { similarity. }\end{array}$ & & \\
\hline $\begin{array}{l}\text { 5.Blocking antibody: } \\
\text { Antibody, that does not have a } \\
\text { reaction when combined with an } \\
\text { antigen, but prevents other } \\
\text { antibodies from combining with that } \\
\text { antigen }\end{array}$ & & \\
\hline
\end{tabular}


The second phase of increased insulin sensitivity or decreased IR, which follows is the apparent return to normalcy of BS. This is characterized clinically by erratic insulin response to exogenous insulin with BS levels reaching with less than the insulin dose required before vaccination, indicating, the decreased IR/ increase insulin sensitivity. Serologically this stage corresponds to Ig M negative and IgG positive stage of the natural infection by SARS CoV 2 (tale 2). Not only the insulin doses needed to be adjusted accordance with corresponding BS Levels. Still Even with extra care and adjustment of insulin doses at BF, and dinner, still, 4 episodes of near hypoglycaemia occurred during the study period. The occurrence of hypoglycaemic episodes even when insulin dose is within the pre vaccination doses. This is due to increased sensitivity to insulin or by decreased binding of antibodies, other than the IAs, (as seen above in the case of waning titers of Ig M). This increased insulin sensitivity I could be due to o be due to the Ig G type of antibodies produced, following vaccination, acting as blocking antibodies which Antibody, that does not have a reaction when combined with an antigen, but prevents other antibodies from combining with that antigen. It is already seen that the neutralizing antibodies to $\mathrm{db}$ domain formed are only unto $15 \%$ whereas the other $85 \%$ are of other than neutralizing type. When these blocking antibodies combine with the antigenic insulin, the anti-insulin antibodies that are already attached to insulin are displaced. This is made possible because of the anti-insulin antibodies being of low sensility. The blocking Ig $\mathrm{G}$ antibodies being high sanative and low-capacity type, displace the insulin antibodies (IAs) and attach themselves to insulin. Thus, the insulin not bound to IAs are released and the sensitivity of insulin is, thus increased. This stage is found to last for about 6 weeks. The exact duration of existence in blood of the blocking antibodies Is not known, but the end of this stage of hypoglycaemia after about 6 weeks from the stage of apparent return to normalcy, referred to in the table 2, suggests that the blocking Ig G antibody may also last for about 6 weeks. This is in contrast to the neutrising antibodies which have a life span more than at least, 6 months, or more. The similarity of insulin restence of this stage and the Ig G blocking antibodies lends support to probability of cause and effect. Thus, the disappearance of these blocking antibodies coincides with the end of the stage of hypoglycaemia, and beginning of the stage of permanent return to normal of the BS levels/IR /and the insulin dose to the prevaccination levels suggesting connection between the both.

\section{Conclusion}

A hypothesis is proposed to explain the clinical syndrome of biphasic glycaemic disturbance, reported recently, by this author, in a patient with DM 2, who has moderate resistance to exogenous insulin. It is conceived, that the induction of successive types of antibodies of IgM and Ig G classes, following vaccination for Covid 19, interact in such a way with the administered insulin, as to increase and later decrease the IR. This results in the initial hyperglycaemia and later hypoglycaemia respectively, observed during the course of the syndrome. It is proposed that, by the nature of the antibodies produced following the vaccination to Covid 19, the Ig M, potentiates and the Ig G, that follows, acts as blocking antibody, reducing the IR by preventing the binding of insulin to its antibody. The duration of the respective antibodies coincides with the duration of the various stages of the syndrome, lending further support to the hypothesis. These contentions need to be confirmed by future research.

\section{Compliance with ethical standards}

\section{Disclosure of conflict of interest}

No conflict of interest.

\section{References}

[1] Cefalu WT. Insulin resistance: cellular and clinical concepts. Exp Biol Med (Maywood) 2001; 226: 13. [PubMed] [Google Scholar].

[2] Reaven G. The metabolic syndrome or the insulin resistance syndrome? Different names, different concepts, and different goals. Endocrinol Metab Clin North Am. 2004; 33: 283-303. [PubMed] [Google Scholar].

[3] Shipp JC, Cunningham RW, Russell RO, Marble A: Insulin resistance: clinical features, natural course and effects of adrenal steroid treatment: Medicine (Baltimore). 1965; 44: 165-184. Google Scholar Crossref PubMedT R.

[4] American Diabetes Association Consensus development conference on insulin resistance. Diabetes Care. 1997; 21: 310-314 [Google Scholar] American Diabetes Association Consensus development conference on insulin resistance. Diabetes Care. 1997; 21: 310-314. [Google Scholar] Incidence

[5] Lutsey PL, Steffen LM, Stevens J. Dietary intake and the development of the metabolic syndrome: the Atherosclerosis Risk in Communities study. Circulation. 12 Feb 2008; 117(6): 754-61. 
[6] Parker VE, Semple RK. Genetics in endocrinology: genetic forms of severe insulin resistance: what endocrinologists should know? Eur J Endocrinol. 12 Sep 2013; 169(4): R71-80.

[7] Semple RK, Savage DB, Cochran EK, Gorden P, O'Rahilly S. Genetic syndromes of severe insulin resistance. Endocr Rev. Aug 2011; 32(4): 498-514.

[8] Musso C, Cochran E, Moran SA, Skarulis MC, Oral EA, Taylor S, Gorden P. Clinical course of genetic diseases of the insulin receptor (type A and Rabson-Mendenhall syndromes): a 30-year prospective. Medicine (Baltimore). 2004; 83(4): 209-222.

[9] Flier JS. Lilly Lecture: syndromes of insulin resistance. From patient to gene and back again. Diabetes. 1992; 41: 1207-19.CAS Article PubMed Google Scholar.

[10] Arioglu E, Andewelt A, Diabo C, Bell M, Taylor SI, Gorden P. Clinical course of the syndrome of autoantibodies to the insulin receptor (type B insulin resistance): a 28-year perspective. Medicine (Baltimore). 2002; 81: 87100.CAS Article Google Scholar.

[11] Nakamura F, Taira M, Hashimoto N, Makino H, Sasaki N. Familial type C syndrome of insulin resistance and short stature with possible autosomal dominant transmission. Endocrinol Jpn. 1989 Jun;36(3):349-58.PMID: 2684618.

[12] Kahn CR, Rosenthal AS, Immunologic reactions to insulin: insulin allergy, insulin resistance, and the autoimmune insulin syndrome. Diabetes Care. 1979; 2: 283- 295. Google Scholar Crossref PubMed 217 Grunfeld C, Insulin resistance: pathophysiology, diagnosis, and therapeutic implications,Special Top Endocrinol Metabol. 1984; 6: 193-240. Google Scholar.

[13] Davidson JK, DeBra DW, Immunologic insulin resistance. Diabetes. 1978; 27: 307-3183. 3. Ovalle F. Clinical approach to the patient with diabetes mellitus and very high insulin requirements. Diabetes Res Clin Pract. 2010; 90: 231-242. [PubMed] [Google Scholar]

[14] Berson SA, Yalow RS, Bauman A, Rothschild MA, Newerly K. Insulin-I131 metabolism in human subjects: demonstration of insulin binding globulin in the circulation of insulin treated subjects. Journal of Clinical Investigation. 1956; 35: 170-190. [PMC free article] [PubMed] [CrossRef] [Google Scholar]

[15] Davidson JK, DeBra DW Immunologic insulin resistance. Diabetes. 1978; 307-318 Google Scholar. Crossref PubMed

[16] shizuka T, Ogawa S, Mori T, Nako K, Nakamichi T, Oka Y, Ito S. Characteristics of the antibodies of two patients who developed daytime hyperglycemia and morning hypoglycemia because of insulin antibodies. Diabetes Research and Clinical Practice. 2009; 84: e21-e23. [PubMed] [CrossRef] [Google Scholar]

[17] Zhao TY, Li F, Xiong ZY. Frequent reoccurrence of hypoglycemia in a type 2 diabetic patient with insulin antibodies. Molecular Diagnosis and Therapy. 2010; 14: 237-241. [PubMed] [CrossRef] [Google Scholar]

[18] Xiaolei Hu and Fengling Chen.Exogenous insulin antibody syndrome (EIAS): a clinical syndrome associated with insulin antibodies induced by exogenous insulin in diabetic patientEndocr Connect. Jan 2018; 7(1): R7-R55. Published online 2017 Dec 12.

[19] Shen Y, Song X, Ren Y. Insulin autoimmune syndrome induced by exogenous insulin injection: a four-case series. BMC Endocr Disord. 2019; 19: 148.

[20] Miho Hirano, Hiroshi Arima, and Yutaka Oiso, Immunological Insulin Resistance Due to Insulin Antibodies Developed After Cessation of Insulin Therapy in a Patient With Type 2 DiabetesDiabetes Care. Nov 2008; 31(11): e84-e84.

[21] Jain N, Savani M, Agarwal M, Kadaria D. Methimazole-induced insulin autoimmune syndrome. Ther Adv Endocrinol Metab. 2016; 7(4): 178-81.

[22] DeFronzo RA, Tobin JD, Andres R. Glucose clamp technique: a method for quantifying insulin secretion and resistance. Am J Physiol. Sep 1979; 237(3): E214-23.

[23] Kaul K, Apostolopoulou M, Roden M. Insulin resistance in type 1 diabetes mellitus. Metabolism. 2015; 64(12): 1629-1639.

[24] Bacha F, Klinepeter Bartz S. Insulin resistance, role of metformin and other non-insulin therapies in pediatric type 1 diabetes. Pediatric Diabetes. 2016; 17: 545-558. [PubMed] [CrossRef] [Google Scholar]

[25] Kaul K, Apostolopoulou M, Roden M. Insulin resistance in type 1 diabetes mellitus. Metabolism. 2015; 64(12): 1629-1639. [PubMed] [CrossRef] [Google Scholar] 
[26] Minges KE, Whittemore R, Grey M. Overweight and obesity in youth with type 1 diabetes. Annu Rev Nurs Res. 2013; 31: 47-69.

[27] Ferrannini E, Mari A: How to measure insulin sensitivity. J Hypertens. 1998; 16: 895-906. PMCID: PMC428776313.www.ncbi.nlm.nih.gov > articles > P...157 Andersen 00, Clinical significance of antiinsulin-antibodiesAct Endocrinol1976.205(Suppl) 231-243

[28] Kahn CR, Rosenthal AS, Immunologic reactions to insulin: insulin allergy, insulin resistance, and the autoimmune insulin syndrome. Diabetes Care. 1979; 2: 283- 295. Google Scholar Crossref PubMed 217 Grunfeld C, Insulin resistance: pathophysiology, diagnosis, and therapeutic implications.

[29] Deforms RA, Tobin JD, Andres R. “Glucose Clamp Technique: a Method for Quantification Insulin Secretion and Resistance.” Am. J. Physiol. 1979; 237: E214-E223.

[30] Manish Gutch, Sukriti Kumar, Syed Mohd Razi, Kumar Keshav Gupta, and Abhinav Gupta. Assessment of insulin sensitivity/resistance.Indian J Endocrinol Metab. Jan-Feb 2015; 19(1): 160-164. Devlin JG Evidence for the existence of an IgM immuno-globulin to insulin. Ir J Med Sci. 1966; 6: 507-510.

[31] Andersen 00, Clinical significance of anti-insulin-antibodiesActa Endocrinol. 1976; 205: 231-243164.

[32] Grammer LC, Roberts Buchanan,IA, Fitzsimons R. Metzger BE, Patterson R.Specificity of immunoglobulin E and immunoglobulin $\mathrm{G}$ against human (recombinant DNA) insulin in human insulin allergy and resistance. J Lab Clin Med. 1987; 109: 141-146 .Google Scholar PubMe.

[33] Patterson R, Mellies CJ, Roberts M, Immunologic reactions against insulin. II. IgE anti-insulin, insulin allergy and combined IgE and IgG immunologic insulin resistance.J Immunol. 1973; 110: 1135 - 1145159.

[34] Faulk WP, Karam JH,Fudenberg HH, Human anti-insulin antibodies.J Immunol. 1971; 106: 1112-111160. Reisman RE, Wicher K, Arbesman CE. Immunotherapy with antigen E. ${ }^{1}$ 969. J Allergy. 44: i2-95. Faulk WP, Karam JH,Fudenberg HH, Human anti-insulin antibodies.J Immunol 1971; 106: 1112-111.

[35] Reisman RE, Wicher K, Arbesman CE. Immunotherapy with antigen E. ${ }^{1}$ 969. J Allergy. 44: i2-95

[36] Kniker WT, Grodsky G, Forsham P. Immunogenic vasculitis: is it part of diabetes mellitus? In: Kimura SJ, Caygill WM, eds. vascular complications of diabetes mellitus. 1967St. Louis, MO C.V. Mosby Company.

[37] Hanauer A, Batson J. Anaphylactic shock following insulin injection: case report and review of the literature. Diabetes. 1961; 10: 105-110. Google Scholar

[38] Federlin K. Kelcorsky H, Maser E, Clinical aspects of immunity to insulin. In: Keck RK, Erb P, eds. Basic and clinical aspects of immunity to insulin.

[39] 194 deShazo RD, Boehm TM, Kumar D, Galloway JA, Dvorak HF, Dermal hypersensitivity reactions to insulin: correlations of three patterns to their histopathology. J Allergy Clin Immunol. 1982; 69: 229-237.

[40] deShazo RD . Insulin allergy and insulin resistance: two immunologic reactions.P36stgrad Med. 1978.

[41] ASV Prasad. COVID 19 vaccine induced glycaemic disturbances in DM2 -A Case Report. World Journal of Advanced Research and Reviews. 2021; 10(03): 149-156.RICHARDS FF, KonIGSBERG WH, ROSENSTEIN RW, VARGA JM. ON THE SPECIFICITY OF ANTIBODIES. SCIENCE. 17 JAN 1975; 187(4172): 130-7.

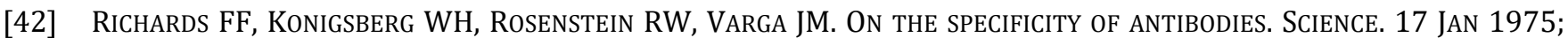
187(4172): 130-7. Schroer JA, Bender T, Feldmann RJ, Kim KJ. Mapping epitopes on the insulin molecule using monoclonal anti bodies. Eur J Immunol. Sep 1983; 13(9): 693-700.

[43] Schroer JA, Bender T, Feldmann RJ, Kim KJ. Mapping epitopes on the insulin molecule using monoclonal antibodies. Eur J Immunol. 1983 Sep;13(9):693-700. doi: 10.1002/eji.1830130902. PMID: 6193965Lain J. East, Frank R. N. Gurd et al. The Antigenic structure of proteins: Ann. Rev. Immune . 1984; 2:67-101.

[44] Pinilla C, Martin R, Gran B, Appel JR, Boggiano C, Wilson DB, Houghten RA. Exploring immunological specificity using synthetic peptide combinatorial libraries. Curr Opin Immunol. Apr 1999; 11(2): 193-202.

[45] L Mortara, H Gras-Masse, C Rommens, A Vene. -Type 1 CD4+ T-Cell Help Is Required for Induction of Antipeptide Multispecific Cytotoxic T Lymphocytes by a Lipopeptidic Vaccine in Rhesus Macaques .Journal of ..., - Am Soc Microbiol. 1999. 